INNOVACIÓN

\title{
El cine ingresa a las aulas de derecho: La emancipación de Tony Manero (2008)
}

\author{
Cinema entra em salas de aula de direito: \\ A emancipação de Tony Manero (2008) \\ Cinema enters the law classrooms: \\ The emancipation of Tony Manero (2008)
}

\author{
Camilo Arancibia Hurtado \\ Universidad de Valparaíso, Chile
}

\begin{abstract}
RESUMEN Este artículo pretende fundamentar desde la didáctica y la estética la inclusión del visionado de películas en las aulas de derecho. Mediante el análisis de la película Tony Manero (2008) del director Pablo Larraín, se abordarán, en primer lugar, las características que posee la clase magistral trascendente como espacio abierto a distintos intervinientes, medios y saberes (en contraste con la clase magistral meramente expositiva), para luego presentar la teoría de Jacques Rancière sobre el régimen estético del arte que, en su aplicación al cine, se funda en lo que él llama la «tragedia en suspenso». Esta conjunción interdisciplinaria nos dará la pauta para volver a comprender fenómenos pertenecientes al derecho (en este caso, la violencia) en su total complejidad, permitiendo así la emancipación intelectual del estudiante y del espacio de enseñanzaaprendizaje.
\end{abstract}

PALABRAS CLAVE Clase magistral trascendente, cine y derecho, régimen estético del arte, violencia, emancipación intelectual.

RESUMO Este artigo tem como objetivo apoiar a inclusão da exibição de filmes nas aulas de Direito desde a didática e a estética. Através da análise do filme Tony Manero (2008) do diretor Pablo Larraín, serão abordadas as características da master class transcendente como um espaço aberto a diferentes participantes, mídias e saberes (ao contrário da masterclass meramente expositiva) para então apresentar a teoria de Jacques Rancière sobre o regime estético da arte que, em sua aplicação ao cinema, se baseia no que ele chama de «tragédia do suspense». Essa conjunção interdisciplinar nos dará o guia para re-compreender fenômenos pertencentes ao direito (no caso, a violência) 
em sua total complexidade, permitindo assim a emancipação intelectual do aluno e do espaço de ensino-aprendizagem.

PALAVRAS-CHAVE Masterclasse transcendente, cinema e direito, regime estético da arte, violência, emancipação intelectual.

\begin{abstract}
This work aims to base the didactics and aesthetics of the inclusion of film viewing in law classrooms. Through the analysis of the film Tony Manero (2008) by director Pablo Larraín, the characteristics of the transcendent master class as an open space for different participants, media and knowledge (in contrast to the master class merely expository) will be addressed, and then present Jacques Rancière's theory of the aesthetic regime of art, which, in its application to cinema, is based on what he calls the «suspense tragedy». This interdisciplinary conjunction will give us the guideline to re-understand phenomena belonging with Law (violence in this case) in its full complexity, thus allowing the intellectual emancipation of the student and the teaching-learning space.
\end{abstract}

KEYWORDS Transcendent masterclass, cinema and law, aesthetic regime of art, violence, intellectual emancipation.

Bailar es pensar con el cuerpo.

-Nicanor Parra

\title{
Introducción
}

En su ensayo «Escritores, intelectuales, profesores», Roland Barthes, ese agudo observador de la realidad, destina un acápite a las preguntas que se suscitan en los debates intelectuales. Señala que preguntar consiste en «desear saber una cosa», pero que, en el contexto reseñado, eso no se produce, ya que los debates están tan codificados como las disputas escolásticas: en ellos se encuentran siempre papeles de servicio (el «sociologista», el «goldmaniano», el «telqueliano», etcétera) (Barthes, 1974: 95). El espacio común se vuelve pétreo, es decir, sin posibilidad de observar los fenómenos integralmente, cumpliendo cada personaje su rol. Se produce lo que en palabras de Jacques Rancière se denomina «el atontamiento», esto es, la subordinación de las inteligencias a otras que se entiende que son superiores, lo cual es un caso patente de eliminación de la emancipación en el aula (Rancière, 2003: 25).

Esta cuestión es analogable a lo que ocurre en las salas de clases de derecho, donde el contenido a transmitir atrapa al docente y al estudiante en un círculo uróboro, de eterno retorno y puesta en escena. Una explicación para esto es que el saber jurídico se transmite como si se tratara de una serie de verdades frente a las cuales solo caben 
dos actitudes complementarias: aprenderlo de memoria y recordarlo (Valle, 2002: 363). El medio de enseñanza tradicional de esta forma de concebir el derecho es la clase magistral en su versión «meramente expositiva» (Elgueta y Palma, 2014: 909). Así, obedece a una opción científica y dogmática de tipo positivista que se propone enseñar las instituciones y los conceptos jurídicos como han sido extraídos de las «verdades o esencias jurídicas» (Valle, 2002: 365).

La clase magistral ha sido estudiada por los profesores Elgueta y Palma, quienes han hecho una reformulación y un mejoramiento que han denominado «clase magistral trascendente o formativa». Esta se establece como un espacio de apertura a la clausura que significa la clase magistral meramente expositiva, ya que, entre otras cosas, fomenta la intervención del estudiante, se combina con otros medios de entregar información (tecnologías de la información y la comunicación) y no existe una posición dominante del saber por parte del profesor, sino que, al contrario, este se muestra dispuesto al diálogo y a la confrontación de ideas (Elgueta y Palma, 2014: 918-919). Mirada así, esta clase magistral renovada se configura como un espacio óptimo para complejizar la materia a impartir en clases.

Ahora, las preguntas son cómo lograr la problematización deseada y cómo salir de la disputatio meramente ornamental. Existen muchas vías de abordar esta cuestión (Gómez, Rubio y González, 2019:37-57). Una de ellas es la utilización del arte en el aula.

Desde 2015 se ha trabajado con el Seminario de arte y derecho de la Escuela de Derecho de la Universidad de Valparaíso en las relaciones que existen entre una y otra disciplina, lo que desembocó, en 2017, en la primera cátedra de derecho y literatura en la región y en un artículo relativo a la contribución del género literario del cuento en la didáctica del derecho (Arancibia, 2019: 535-555).

$\mathrm{El}$ arte puede prestar un servicio importante en la enseñanza-aprendizaje del derecho, ya que, como señala el filósofo Jacques Rancière (2009: 7), la estética es «un modo de articulación entre maneras de hacer, formas de visibilidad de esas maneras de hacer y modos de pensabilidad de sus relaciones», lo que, en otras palabras, quiere decir que el arte permite pensar nuevas posibilidades donde al parecer solo habría una. El cine, en particular, se presta como un aliado perfecto para la concreción de esta idea. Es lo que señala Ost (2006: 335) para el caso de la literatura:

Mientras que el derecho codifica la realidad, institucionalizándola en una estrecha red de requisitos previamente acordados, contemplados en un complejo sistema de límites y prohibiciones, la literatura, en cambio, libera las posibilidades del pensamiento, suspende nuestra certidumbre, despierta nuestra energía de su letargo, sacude identidades y convenciones y nos lleva a una encrucijada donde todo puede comenzar de cero.

En este artículo desarrollaremos las ideas de los profesores Elgueta y Palma sobre la clase magistral trascendente, y del filósofo Jacques Rancière en torno al arte y 
al cine a partir del análisis detallado de la película chilena Tony Manero (2008) del director Pablo Larraín. El abordaje interdisciplinario mostrará paso a paso el fundamento didáctico y estético de la tesis planteada, esto es, que el cine en las escuelas de derecho puede servir como gatillante de una emancipación intelectual del aula.

\section{Una historia violenta: La clase magistral (meramente expositiva) como un espacio clausurado}

Tony Manero es una película incómoda. Hay algo en su estética decadente, en su casi mudo personaje principal y en el entorno derruido que habita, que lleva al planteamiento de muchas preguntas.

Esta película narra la historia de un hombre marginal (Raúl Peralta Paredes de 52 años), cuyo objetivo es ganar el concurso de dobles de Tony Manero que la televisión chilena en dictadura ofrece. Por supuesto, la historia subterránea es que, para lograr ese fin, Peralta comete cuatro homicidios muy violentos y varios robos. Trabaja como bailarín en un restaurante del barrio y se desliza por la ciudad buscando las partes (luces, vidrios, madera) que compondrán el improvisado escenario de sus coreografías obtenidas del visionado obsesivo de la película Fiebre de sábado por la noche (1977).

De hecho, lo único que puede conmover a Peralta es la ida al cine a ver, una y otra vez, la mentada película. Archiva los diálogos en su cabeza, llora cuando el filme así lo dicta y copia las escenas de baile a la perfección.

Si tomamos como eje central de estudio la violencia que se muestra en esta película, entonces la aproximación puede realizarse desde diferentes ramas del derecho. Pienso en Introducción al Derecho (a propósito de la coerción y el monopolio de la fuerza), Sociología Jurídica (marginalidad y riesgo social; conducta y anomia), Filosofía del Derecho (derechos humanos y pobreza, la desobediencia civil, la protesta), Teoría Política (las teorías de la formación del Estado), Derecho Penal (diversos delitos cometidos con esa característica, naturaleza de la prisión, la venganza, teoría de la pena, etcétera), entre otras.

Como sea, una clase magistral tradicional tenderá a agotar el contenido propuesto para la lección y si se hiciera espacio para el visionado del filme en comento, las reflexiones tenderían a cumplir estrictamente con la parte formal del programa de la asignatura. Pareciera que no podría ser de otra manera al tratarse de esta clase.

El académico de la Universidad de Valparaíso Agustín Squella elaboró en 1988 una descripción de la cultura jurídica interna chilena que actualmente se ha mantenido incólume en sus aspectos centrales. Dividió esta categorización en doce hipótesis, donde la última se refería a la enseñanza del derecho. Señalaba Squella (1988: 46) que el método que se utiliza es «la clase expositiva, que intenta transmitir oralmente a los alumnos la totalidad de un material que ha sido previa y completamente elaborado por el respectivo docente». En cuanto a los medios, indica que «se entiende que los 
únicos medios de enseñanza son los propios continentes normativos del derecho (códigos, leyes, reglamentos, etcétera) y los textos que exponen y comentan, en forma sistemática, esos mismos cuerpos normativos».

Diecisiete años después, Rodrigo Coloma (2016: 4) realizó una descripción similar de lo que acontecía en las aulas de las Escuelas de Derecho. Comentando las críticas que se hacen a la forma en que se lleva a cabo la enseñanza tradicional, señaló:

Entre los blancos predilectos de los autores podemos hallar el carácter enciclopédico de la formación en ciencias jurídicas [...] el énfasis exagerado en la memorización como objetivo de aprendizaje [...] la obsolescencia de los programas de las asignaturas y la escasez de interdisciplinariedad de los aprendizajes; el abuso de la clase magistral como forma de interacción entre profesor y estudiante; como también, la transmisión de una concepción del abogado como mero aplicador de la legislación.

Similar apreciación tiene Aldo Valle (2006: 88-89) sobre el tema:

El fetiche por el contenido se traduce en la exigencia y la propensión a entregar en el pregrado todos los contenidos legislativos existentes en todas las materias. Los profesores de las principales ramas de formación dogmática como derecho civil, procesal y penal se juegan la vida si no pasan todas y cada una de las disposiciones, no de las instituciones, de sus respectivos códigos.

Siguiendo a la profesora María Elena Cárdenas (2007: 90-91), lo citado se puede resumir en cuatro puntos: i) se privilegia el discurso de los profesores; ii) provoca pasividad de los estudiantes; iii) induce a la memorización de datos encima de una labor analítica de la información; y iv) inhibe la actitud crítica de los estudiantes frente a las afirmaciones que formulan los docentes.

Todo lo anterior da cuenta de una concepción estática del derecho y, por lo mismo, simple, sin recovecos, prístina frente a los ojos del estudiante. El derecho se muestra como una obra legislativa ya concluida o contenida en ciertas entidades que se debe conocer o descubrir (Valle, 2002: 360) Así, el profesor se convierte en mero «explicador» de lo que los alumnos podrían aprender igualmente y, por ende, la capacidad intelectual de los mismos, amén de su autonomía, se ve mermada. No hay posibilidad de que el estudiante «tenga el valor de servirse de su propia razón». Esta ya está dominada de antemano.

Siguiendo este modelo de clase magistral, analizaremos la película de la siguiente manera: los crímenes, necesarios para la construcción del escenario de Peralta, tienen como objeto común hacer del personaje el mejor doble, el mejor calco, la mejor copia del Manero estadounidense. La pregunta, entonces, asaltaría de inmediato: ¿Por qué mata y roba Peralta? La respuesta de los estudiantes, como hemos dicho, uniría en relación de causalidad lo siguiente: Peralta comete crímenes porque busca tener un escenario para practicar, lo que luego le permitirá ganar el concurso de dobles. 
Con esa respuesta podríamos satisfacer formalmente el objetivo de la clase (el programa de la asignatura se ejecutó), pero la respuesta no parece tan obvia, ya que hay un marco contextual que no ha sido develado. Y es aquí donde la clase magistral trascendente hace su aparición.

\section{Se escucha la sangre caer: La clase magistral (trascendente o formativa) como un espacio abierto}

Este tipo de clase, que en su esencia manifiesta una disposición a la apertura (de intervinientes, medios, saberes), permite que se descubra un claro por donde podemos analizar de mejor forma las instituciones y fenómenos jurídicos. Señalan los profesores Elgueta y Palma (2019: 118) que en esta clase el profesor que está interesado «en la transmisión del saber recurre no solo a un discurso lineal sobre la materia, sino también a ejemplos, a la manifestación práctica del contenido y a la vivencia del mismo».

Más aún, el profesor conecta el contenido con el «entorno en el que se desenvuelve el acto educativo», lo que implica, luego, analizar los «fundamentos jurídicos, esto es, mostrar el sustento que podrían tener en la normativa vigente o histórica» (Elgueta y Palma, 2019: 157).

El ejemplo que ofrecen los académicos aclarará el punto: se preguntan si es legítimo que se sancione el robo de un bien de primera necesidad, como el alimento, con una mayor pena que los delitos económicos de cuello y corbata. En este caso no se trata solo de presentar el concepto, requisitos, elementos y características del tipo penal, sino que el esfuerzo se dirige a revelar cómo opera el ordenamiento jurídico en sus raíces, ya que este no se presenta como neutro, sino que ostenta una moral que busca reforzar.

Si lo anterior es cierto, entonces el análisis de la película no puede quedarse en lo que los estudiantes pudieran saber de cualquier manera, sino que es necesario ahondar en aspectos más profundos en clases.

Para esto es relevante que el examen se detenga en ciertas particularidades del contenido. El análisis de la siguiente escena puede servir de puntapié para hundirse en el estudio de la violencia.

En la calle unos ladrones atacan a una señora y Peralta, que observa todo desde su ventana, baja rápidamente las escaleras, sale de su casa y la ayuda a levantarse. Esta le agradece y encarecidamente le pide que la acompañe a casa. Peralta accede y la toma del brazo para evitar que se caiga. Al llegar al hogar de la señora, el protagonista se queda mirando los adornos que posee y repara en la televisión a color, un lujo para la época. La señora le conversa y Peralta se sienta a su lado observando las imágenes televisivas que, en ese momento, muestran al dictador Pinochet declarando la «cueca» como baile nacional. Ambos se quedan callados y, de pronto, Peralta golpea a la señora fuertemente en la cabeza. La siguiente escena da cuenta de la repetición 
constante de golpes. Unos tras otros se estampan contra la cara de la dueña de casa. Luego, Peralta se limpia las manos, enciende un cigarro y sentado mira la televisión. La siguiente escena lo muestra cargando en sus hombros el aparato por las desiertas calles de Santiago.

Lo primero que salta a la vista en esta violenta escena es la brutalidad del hombre. No podemos entender cómo una persona primero se muestra afable con otra y luego la termina matando. Hay algo ahí que chirría, que es difícil de solucionar.

Ciertamente, comete el delito con alevosía, a traición u obrando sobre seguro, y lo que escuchamos (porque la escena solo muestra la cara de Peralta) es la sangre que se esparce y que da cuenta de ello.

El problema de enfocar el examen de la escena solo desde la sangre que corre es que el estudio se muestra limitado. La clase magistral trascendente, como espacio abierto de discusión, propone el ingreso de nuevos soportes de presentación de la información, diferentes al texto impreso (Elgueta y Palma, 2019:159). Uno de ellos es el cine, ¿pero qué tipo de cine? ¿Qué característica debe poseer? Congelemos la escena un momento y abordemos las reflexiones de Jacques Rancière sobre esto.

\section{¿Se escucha la sangre caer? Régimen estético del arte y suspenso}

Este filósofo cimenta parte importante de su obra en la pregunta acerca de qué es arte imbricando su respuesta con lo político. Para entender sus razonamientos es necesario esclarecer, primeramente, un concepto fundamental de sus tesis, que es «el reparto de lo sensible».

Rancière (2009: 9) lo define como «ese sistema de evidencias sensibles que al mismo tiempo hace visible la existencia de un común y los recortes que allí definen los lugares y las partes respectivas». Para este teórico se torna relevante el orden que disponen los cuerpos, tiempos y lugares, y cómo se puede proceder a su redistribución. Si en sus primeras obras se preguntaba por el lugar del obrero confinado en su esfera de trabajador, ahora sus disquisiciones se convierten en un modelo para pensar nuevas formas de comunidad y la participación que a cada cual corresponde en ella. Por esto, lo «sensible» se relaciona directamente con lo político y lo social, no siendo solo algo propio del arte.

En ese sentido, Rancière hace una distinción fundamental entre dos conceptos que se suelen confundir, pero que son radicalmente diferentes: «policía» y "política».

La «policía» es «el conjunto de procesos mediante los cuales se efectúa la agregación y el consentimiento de las colectividades, la organización de los poderes, la distribución de los lugares y funciones, y los sistemas de legitimación de esta distribución» (Rancière, 1996: 44). En ese sentido, la "policía» es la ley, la que instaura el orden.

En directa oposición a ella encontramos la "política», que se configura como una 
irrupción que permite la aparición de sujetos y objetos nuevos. Podemos pensar esta noción en conexión con la distinción de Hannah Arendt (2016: 243) entre "comienzo» y «ejecución» de una acción. Es ella la que, así entendida, permite visibilizar lo que antes no se mostraba o se invisibilizaba. $Y$ es esta característica la que Rancière pone de relieve en relación con el arte.

Para esto, distingue tres grandes regímenes de identificación: ético, poético o representativo y estético. En el primero, el arte se encuentra subsumido en el análisis de las imágenes, por lo que no hay posibilidad de individualizarlo como tal. El segundo, el poético o representativo, concierne a las bellas artes y se supedita a la noción de mímesis que organiza las maneras de hacer, ver y juzgar que, en sus palabras, «se desarrolla en formas de normatividad que definen las condiciones según las cuales las imitaciones pueden ser reconocidas como pertenecientes propiamente a un arte, $\mathrm{y}$ apreciadas, en su marco, como buenas o malas, adecuadas o inadecuadas» (Rancière, 2009: 22-23). Este concepto se podría relacionar con el de «policía». Por último, el régimen estético es el que identifica al arte con un modo de ser sensible propio de los productos del arte. Este es el que nos interesa.

El arte, declara Rancière, puede ser pensado como una forma de inscripción de sentido en la comunidad, permitiendo ver y oír aquello que permanecía oculto o inaudible. Las diferentes prácticas artísticas, al ejercerse, se vuelven formas de visibilidad que intervienen en la distribución general de las maneras de hacer y de ser.

$\mathrm{El}$ arte visto así es uno eminentemente político, que reconfigura el orden dado como natural y que posibilita mostrar un mapa de lo común más amplio que el que la «policía» o el régimen de lo representativo mostraba. El orden se pone en cuestión.

Así, cuando analiza la obra de Gustave Flaubert, pone el acento en la igualdad democrática que logra en sus libros, ya que, por ejemplo, en Un corazón sencillo la protagonista es una criada y no su ama. Por otra parte, en Madame Bovary se hunde en los avatares amorosos y existenciales de una mujer. Ambas son figuras constantemente desplazadas. Señala que para Flaubert no hay distinción entre temas mayores y menores, ni jerarquía entre primer y segundo plano, inventando «otras reglas de adecuación entre el significado de las palabras y la visibilidad de las cosas» (Rancière, 2011). Se trata de una democracia estética que se adelanta a lo que son las democracias actuales. La inclusión de nuevos intervinientes, medios y saberes, permite el acceso a un mundo más complejo y dinámico. La inclusión, asimismo, de una sirvienta en el rol protagónico de una novela, se torna política y radicalmente democrática. Es la democracia radical de las letras. El gran investigador argentino en derecho y literatura Jorge Roggero destaca, en ese mismo sentido, a Derrida y su idea de que «no hay democracia sin literatura, y no hay literatura sin democracia» (Roggero, 2012: 186).

En específico, Rancière ha pensado lo que ocurre con el cine y esta idea del régimen estético. En su libro La fábula cinematográfica repasa la historia del séptimo arte poniendo en cuestión un modo peculiar de organizar las acciones con vistas a 
un determinado efecto estético, que él denomina «la «fábula». La idea de Ranciére es desanclar la intención del creador de una obra de arte y el efecto que quiere imprimirle, para así observar lo que no forma parte del entramado principal de acciones. Hay algo en los «tiempos muertos» ${ }^{1}$ de los filmes que nos dicen algo que no se está diciendo a viva voz y eso hace que, si las integramos al relato principal, las acciones de los personajes en una película, como en la vida misma, no sean siempre claras y se produzcan situaciones abiertas en todas direcciones. Es lo que él llama «la tragedia en suspenso» (Rancière, 2005: 9).

En Tony Manero vemos que el personaje principal deambula por la ciudad, comete sus felonías, tiene escenas de afecto, sexo interrumpido e, incluso, hay una escena donde su pulsión lo lleva a defecar en el traje de Manero que pertenece a un cercano para que este no pueda postular al premio. ¿Cómo entender la conducta del personaje principal?

Rancière, como decíamos, nos invita a volver a mirar, pero esta vez poniendo atención a las tensiones que subyacen en la película. Hay que salir de la acción dramática obvia. Dice este filósofo que lo que debe hacer el cine es extraer una fábula dentro de otra:

Ese trabajo de desfiguración ya lo llevaron a cabo los críticos de arte del siglo XIX [...] cuando vieron, en las escenas religiosas de Rubens, las escenas burguesas de Rembrandt o los bodegones de Chardin, una misma dramaturgia en la que el gesto de la pintura y la aventura de la materia pictórica ocupaban un lugar privilegiado, relegando a un segundo término el contenido figurativo de los cuadros (Rancière, 2005: 16).

Hay aquí un notable desplazamiento de la mirada, que permite encontrar una «verdad interior de lo sensible» que no estaba a la vista. Se hace visible una zona que antes permanecía cubierta, una "textura íntima de las cosas.»

Pensemos en la escena que nuestro autor nos propone: hay un momento de la película El vampiro de Dusseldorf (1931) de Fritz Lang en el que el asesino de niñas es buscado intensamente por sus captores, pero el primero se detiene a observar relajadamente un escaparate, donde ve, en el reflejo, a una menor. El rostro del criminal pasa «del sosiego del paseante anónimo a la mecánica del cazador», develando el delito que se producirá luego. Esta escena, mínima, revela ese contra-efecto que el cine instala, esa suspensión momentánea de la acción, el «esplendor de lo insignificante» que ciega por su revelación. ¿Cómo entender la conducta del personaje principal?

Esta idea puede aplicarse a la escena de Tony Manero que comentamos. En este caso, la tensión se va construyendo desde que Peralta ve la oportunidad de cometer

1. Esto recuerda a la ocurrencia del cineasta Raúl Ruiz (2017:436) en su diario: «Idea para un filme americano: La vida de un hombre de acción usando solo los tiempos muertos». 
un atraco y, luego, se intensifica cuando se encuentra dentro del cuarto de la víctima. Observa con envidia el interior de la casa y, sobre todo, la televisión.

La clave del análisis de la escena está dada por la comparecencia callada entre Peralta y la dueña de casa, cuando ambos miran la televisión. Ahí, aparece Pinochet declarando la cueca como baile nacional. No se trata de un asunto baladí, sino de una muestra simbólica de la refundación total a la que se vio expuesta Chile en esa época. Esta apertura del filme a la vida colectiva mayor desde los gestos más elementales y cotidianos es lo que se produce en las acciones infraordinarias (para ocupar el término de Perec) de los documentales chilenos: Diálogos de exiliados (1975) de Raúl Ruiz, La once (2014) de Maite Alberdi, Aquí se construye (o Ya no existe el lugar donde nací) (2000) de Ignacio Agüero y Obreras saliendo de la fábrica (2005) de José Luis Torres Leiva, entre otros. En fin, no es trivial que aparezca en el primer homicidio de Peralta. Da una razón explicativa de la conducta.

Esto nos permite, entonces, abordar el fenómeno de la violencia en su compleja magnitud.

\section{Una Historia violenta: Modificación cultural de la vida cotidiana}

En esta parte no se trata de realizar el estudio sistemático de la violencia, pero sí me parece pertinente, para completar la secuencia, mostrar desde qué ángulo puede ser analizada en el aula. Esto nos mostrará, para finalizar, una posible ruta de emancipación intelectual.

Como sabemos, la violencia ha sido estudiada por pensadores brillantes. Es cosa de nombrarlos: Walter Benjamin, Hannah Arendt, Georges Sorel, Carl Schmitt, Frantz Fanon y Jan Assmann, entre otros. ${ }^{2}$

Slavoj Žižek (2009:10) también hizo su contribución en una obra donde traza una distinción entre violencia subjetiva y violencia objetiva. Este autor señala que la primera es aquella visible, la practicada por un agente que podemos identificar al instante. La segunda se divide en simbólica, que se ejerce en el lenguaje, y la sistémica, que se produce a consecuencia del funcionamiento económico y político de un país.

De esta forma, si nos preguntamos por la categoría de violencia a aplicar en la escena descrita, el caso, en primera instancia, parece claro: el delito cometido por Peralta se enmarca en la primera categoría con seguridad, es decir, la de violencia subjetiva. El agente es plenamente reconocible y no queda duda alguna de su responsabilidad en el hecho. Las pruebas están ahí y solo cabe recogerlas.

La operación, sin embargo, es más compleja. La primera razón de esto estriba en el contexto de violencia estatal que imponía la dictadura. En la época en que está ambientada la película, 1978, los crímenes clandestinos eran cometidos por la temida Central Nacional de Informaciones (CNI), órgano del gobierno encargado de perseguir y ajusticiar a los opositores del régimen de fuerza. Allanaban las casas, sometían 
a torturas y vejámenes a los ciudadanos, asesinaban impunemente y hacían desaparecer los cuerpos (Comisión Nacional de Verdad y Reconciliación, 1996: 60). La violencia era la forma de expresión del Estado, por ende, el comportamiento de Peralta se podría denominar como coherente con la situación nacional y, de una retorcida manera, "ciudadano»: un Estado que se ha transformado en asesino serial no puede hacer menos que parir homicidas de igual cepa.

Otra aproximación puede hacerse, esta vez, desde el punto de vista económicocultural. La implantación del modelo actual consistió en una apertura económica sin precedentes en nuestra historia nacional, lo que sumado al arribo de masivos capitales extranjeros, produjo un cambio cultural que llevó a decir a uno de los funcionarios y economistas del régimen, Joaquín Lavín (1987: 11), lo siguiente: «se modificaron las formas en que las nuevas generaciones de chilenos viven, piensan, estudian, trabajan y descansan». Así, retomando a Peralta, podríamos agregar «y la forma en que bailan».

Hay una escena impresionante en la película. Se trata de una en la que Peralta comienza a hablar en un inglés muy defectuoso con sus compañeros de baile. Los empieza a interrogar sobre diferentes cosas. Ellos se incomodan, se ríen de él, pero luego todos captamos que está reproduciendo los diálogos del personaje principal de Fiebre de sábado por la noche. Su boca habla otra lengua y su cuerpo la sigue.

Es lo que señala Araujo (2017) sobre el modelo establecido en Chile:

Este impactó en las formas que adquirieron los desafíos estructurales de la vida social, al mismo tiempo que introdujo la imagen de una sociedad perfectamente móvil y competitiva; la valorización de la ambición personal y la confianza en el esfuerzo propio; la entronización de actores fuertemente responsabilizados de su destino personal.

La Historia de Chile ha producido una subjetivación total en Peralta y el modelo cultural extranjero ha empezado a calar hondo no solo en sus desplazamientos utilitarios, sino también en su forma de concebir la dupla medios/fines.

\section{Emancipación intelectual en el aula: Desear saber una cosa}

Esta forma de racionalidad utilitaria, ${ }^{3}$ que permeó la forma en que se enseña en Chile, se ha revelado como dominante en la educación superior y es menester atemperarla, ya que su cometido no se aviene con lo que significa esencialmente una universidad. El filósofo chileno Jorge Millas (1981: 498-498) se refirió al carácter de la misma:

Nadie discutiría [...] que a la universidad, por modo preeminente y casi exclusivo, le compete la movilización social de la ciencia, a través de su capital misión de pre-

3. Nos referimos nuevamente a «las formas en que las nuevas generaciones de chilenos viven, piensan, estudian, trabajan y descansan», palabras de Lavín (1987: 11). 
parar los equipos profesionales y técnicos de entrenamiento superior y de dar a sus estudiantes y difundir la imagen vigente del mundo y su crítica.

El cine, como el derecho, se vale de imágenes para explicar el mundo, pero para dar una imagen vigente del mismo es necesario contar con todos los fotogramas.

Si pudiéramos aislar la escena de la golpiza de Peralta a la dueña de casa, lo veríamos a él repetidamente usando sus puños para maltratarla, pero esta imagen no se correspondería completamente con la realidad, ya que es complejo aislar la violencia que se ve de aquella que no.

Žižek (2009:10) llama la atención sobre este punto cuando menciona que «la cuestión está en que las violencias subjetivas y objetivas no pueden percibirse desde el mismo punto de vista, pues la violencia subjetiva se experimenta como tal en contraste con un fondo de nivel cero de violencia».

Podemos recortar la imagen solo si buscamos la punición penal del infractor. Si, por el contrario, queremos comprender el actuar humano violento, es necesario dar cuenta de los efectos que la implantación de determinados modelos producen en los habitantes de un país, ya que, generando efectos positivos, también producen efectos no deseados.

La cuestión de ofrecer una imagen total del mundo y su crítica no es un asunto banal, ya que se entronca con las preocupaciones de Rancière en torno a la emancipación de los ciudadanos. Define este concepto como «la diferencia conocida y mantenida de las dos relaciones, al acto de una inteligencia que solo obedece a sí misma, aunque la voluntad obedezca a otra voluntad» (Rancière, 2003: 11-12).

En el modelo de clase magistral que estamos siguiendo, es evidente que el profesor tiene la potestad de iniciar el diálogo. Por esto, la voluntad de los estudiantes está en relación con la del docente. Así, no es lo mismo que sujetar las inteligencias de los alumnos a la del maestro. Es en este punto en el que al alumno debe de proveérsele, por parte del profesor, lo necesario para que su entendimiento sea lo más amplio y profundo.

Esto es relevante, ya que, como señala Rancière (2003: 14), es menester que toda persona pueda «formar conciencia de su capacidad intelectual y decidir su uso». Pensada así, la autonomía, que presupone la emancipación intelectual, puede no solo colaborar en la educación del estudiante, sino que permite que el aula, como un todo (intervinientes, medios y saberes), se libere de ciertos usos que actualmente no están cumpliendo su función.

En la misma línea, Elgueta y Palma conciben un aula amable para la sabiduría, en la que «el académico debe contribuir a diferenciar y distinguir las distintas posturas» propiciando el cumplimiento del principio del pluralismo jurídico en el aula. El docente, ahora activo: 
Debe reflexionar sobre la dimensión histórica del derecho y, en consecuencia, sobre la mutación de las costumbres en función de los desafíos sociales que cada generación debe abordar, generando con estas reflexiones, una oportunidad para que los jóvenes estudiantes mediten y debatan sobre los desafíos de su tiempo existencial y los valores que les parecen más apropiados para enfrentarlos» (Elgueta y Palma, 2019: 158).

Acá hay una demostración palpable de que la clase magistral puede realizarse de otra manera, no recortando a un nivel de fondo cero el conocimiento, sino mostrando la complejidad que subyace a las instituciones y a los fenómenos del derecho.

\section{Último paso de baile: Conclusiones}

Los minutos finales de la película se centran en la estética del set de televisión con su juego de espejos y vanidad. Ahí vemos a los ansiosos candidatos a doble de Manero, al público excesivamente entusiasta, el decorado fino, y escuchamos la melosa voz del animador del programa.

Nuestro Tony Manero ha atravesado todas las vallas morales, ha enfrentado sus zonas más oscuras y su cuerpo se ha movido hacia ese fin último, ¿pero lo logrará?

Las universidades en Chile y, en particular, las Escuelas de Derecho, pueden dar un gran paso formativo propiciando una mirada sobre el derecho que lo logre contextualizar en sus zonas más complejas. Para esto, hemos querido poner de relieve los efectos positivos que la clase magistral trascendente puede ofrecer como espacio abierto a nuevas formas y saberes, ya que, así, nuestros alumnos tendrán un aprendizaje que posibilitará su emancipación intelectual. Esto puede ser acicateado de diversas formas, pero pensamos que, por su carácter crítico, el cine puede desempeñar un rol importante.

En ese sentido, el arte puede ofrecer lecturas que no circulan con facilidad en nuestras facultades, permitiendo una oxigenación que nos lleve a considerar el aula no como una discoteca atontadora, sino como un espacio de creación amplio, donde el estudio del derecho consista en una reflexión permanente sobre la coreografía institucional que queremos seguir.

\section{Referencias}

Arancibia, Camilo (2019). «El género literario cuento en la enseñanza-aprendizaje del derecho». En Emilia Jocelyn-Holt y Joaquín Trujillo (editores), Ficciones jurídicas. Derecho y literatura en Chile (pp. 535-555). Santiago: Rubicón.

Araujo, Kathya (2017). «Sujeto y neoliberalismo en Chile: Rechazos y apegos». Nuevo Mundo. Mundos Nuevos. Disponible en bit.ly/3oJKjNl.

ArendT, Hannah (2016). La condición humana. Barcelona: Paidós. 
Barthes, Roland (1974). «Escritores, intelectuales, profesores». En ¿Por dónde empezar?. Barcelona: Tusquets.

CÁRdenas, María Elena (2007). «Ensayo sobre didáctica y pedagogía jurídicas». En David Cienfuegos y María Macías (coordinadores), Estudios en homenaje a Marcia Muñoz de Alba Medrano. La enseñanza del derecho (pp. 87-98). Ciudad de México: Universidad Nacional Autónoma de México.

Coloma, Rodrigo (2016). «El ocaso del profesor Binns. Un ensayo acerca de la enseñanza del derecho en Chile». Ius et Praxis, 11 (1): 133-172. Disponible en bit. ly/2W8torb.

Comisión Nacional de Verdad y Reconciliación (1996). Informe. Volumen I. Tomo I. Santiago: Corporación Nacional de Reparación y Reconciliación.

Elgueta, María Francisca y Eric Palma (2019). Aprendizaje y didáctica del derecho. Ciudad de México: Tirant lo Blanch.

-. (2014). «Una propuesta de clasificación de la clase magistral impartida en la facultad de derecho». Revista Chilena de Derecho, 41 (3): 907-924. Disponible en bit. ly/2W1M4Jl.

Gómez, Taelí, Juan Rubio y Walter González (2019). «Pedagogía de la pregunta en la enseñanza-aprendizaje del derecho como innovación metodológica para desarrollar el pensamiento crítico-complejo: Un análisis de caso». Revista Pedagogía Universitaria y Didáctica del Derecho, 6 (2): 37-57. Disponible en bit.ly/33XBxmD. Lavín, Joaquín (1987). Chile: Revolución silenciosa. Santiago: Zig-Zag.

Millas, Jorge (1981). «Problemas fundamentales de la universidad contemporánea». En Escritos breves, artículos, conferencias, discursos, entrevistas (pp. 493-508). Santiago: Fundación Millas. Universidad de Chile.

Ost, Francois (2006). «El reflejo del derecho en la literatura». Doxa. Cuadernos de Filosofía del Derecho, 29:333-348. Disponible en bit.ly/3oSDSaT.

Pina Fersini, María (2016). «Derecho y violencia: La apuesta de la diferencia». Anuario de filosofía del derecho, 32: 265-295. Disponible en bit.ly/3oziXJw.

Rancière, Jacques (1996). El desacuerdo. Política y filosofía. Buenos Aires: Nueva visión.

-. (2003). El maestro ignorante. Cinco lecciones sobre la emancipación intelectual. Barcelona: Laertes.

-. (2005). La fábula cinematográfica. Reflexiones sobre la ficción en el cine. Barcelona: Paidós Ibérica.

-. (2009). El reparto de lo sensible. Estética y política. Santiago: LOM.

-. (2011). «La política de la literatura». En Política de la literatura. Buenos Aires: Libros del Zorzal. 15-54.

Roggero, Jorge (2012). «Derecho c/ literatura». Revista Filosofía del Derecho, 1 (1): 173-193. 
Ruiz, Raúl (2017). Diarios. Notas, recuerdos y secuencias vistas. Tomo I. Santiago: Ediciones UDP.

SQuella, Agustín (1988). «Documento base del seminario sobre la cultura jurídica chilena: la cultura jurídica chilena». En La cultura jurídica chilena, Santiago: Corporación de Promoción Universitaria.

VALLE, Aldo (2006). «Cultura jurídica y enseñanza del derecho. ¿Creencias o competencias?». Revista Escuela de Derecho, 7 (7): 85-98. Disponible en bit.ly/3qMUd2z.

-. (2002) «El saber jurídico: recuerdo o diálogo». Anuario de filosofía jurídica y social. Sobre la cultura jurídica chilena, 20: 359-371.

ŽıžEK, Slavoj (2009). Sobre la violencia. Seis reflexiones marginales. Buenos Aires: Paidós.

\section{Sobre el autor}

Camilo Arancibia Hurtado es abogado, magíster en Derecho de la Universidad de Chile, máster en Literatura Comparada: Estudios Literarios y Culturales de la Universidad Autónoma de Barcelona y estudiante de doctorado en Filosofía de la misma casa de estudios. Además, es profesor de Derecho y Literatura, y de Derecho Civil en la Escuela de Derecho de la Universidad de Valparaíso. Su correo electrónico es camilo.arancibia@uv.cl. (D) https://orcid.org/oooo-0oo1-7484-3068. 
